\title{
Associations between Leisure Activities and HIV Risk Behaviors among Rural Migrants in Urban China
}

\author{
Xinguang Chen ${ }^{1}$, Xiaoming $\mathrm{Li}^{1}$, Bonita Stanton ${ }^{1}$, Xiaoyi Fang ${ }^{2}$, Danhua Lin $^{2}$, Rong Mao ${ }^{3}$ \\ ${ }^{1}$ Wayne State University, Michigan \\ ${ }^{2}$ Institute of Developmental Psychology, Beijing Normal University \\ ${ }^{3}$ Institute of Mental Health, Nanjing University
}

\begin{abstract}
Although much has been documented on factors affecting HIV risk behavior among rural-to-urban migrants in China, data are lacking on the impact of leisure activities. In this study, we examined the association between leisure activities and HIV risk behavior among a sample of rural-to-urban migrants from two large cities (Beijing and Nanjing) in China. Cross-sectional data were analyzed for a sample of 4,085 participants aged 18 to 30 years $(40.5 \%$ females $)$. Findings from the analysis indicated that although the migrants worked long hours, they engaged in a number of activities when they did not work, including watching television (60.2\%), reading (59.1\%), sleeping (55.6\%), and chatting with friends and co-workers (45.0\%). Multiple regression analysis indicated that reading, doing chores (females only), listening to radio programs/audio CDs (male only) were associated with reduced likelihood of HIV risk behavior while playing cards in groups, visiting entertaining installments, watching videos (including Xrated, males only), and wondering around (females only) were associated with increased likelihood of HIV risk behavior. Findings of this study suggest that constructive and individualized activities (e.g., reading, listening to radios, and doing chores) may prevent migrants from engage in HIV risk behaviors while group and entertaining activities related to drugs and sex may increase the odds for migrants to engage in HIV risk behaviors. Prevention research should consider leisure activities as both an influential factor (including time trends and gender differences) for program development and an important venue for program delivery.
\end{abstract}

(C) 2009 Californian Journal of Health Promotion. All rights reserved.

Keywords: China, Leisure Activities, HIV risk behaviors, Rural Migrants

\section{Rural-to-Urban Migration and the HIV Epidemic in China}

Research findings from diverse sources across the globe indicate that population migration may serve as a bridge for HIV spreading between the county/place of origin and the country/place of destination (Lurie, Williams, Zuma, MkayaMwamburi, Garnett, \& Sturm et al., 2003; Sanchez, Lemp, Magis-Rodriguez, BravoGarcia, Carter \& Ruiz. 2004; Soskolne \& Shtarkshall, 2002; Weine , Bahromov \& Mirzoev, 2008). It is not the migration itself, but migration-related risk behaviors that increase the likelihood for the non-infected migrants to be infected by HIV and for the infected migrants to pass the virus to others. Substance use, including tobacco, alcohol, and drugs (Chen, Stanton, Li, Fang, Lin, Xiong, 2009; Weine , Bahromov \& Mirzoev, 2008) and risky sex, including commercial sex, having sex with multiple partners, and having sex without a condom (Lin, Li, Yang, Fang, Stanton \& Chen, 2005; Sanchez, Lemp, Magis-Rodriguez, BravoGarcia, Carter \& Ruiz. 2004) are two types of HIV risk behaviors commonly observed among migrants in various counties/places.

The market-oriented economic reform emerged in 1978 in China and the subsequent relaxation of the Hukou (Household Registration) System by the country in 1989 resulted in a large scale 
and sustained domestic rural-to-urban migration in China (Wu \& Treiman, 2004; Yang, 2003; Ying, 2003). According to the One-perThousand Chinese Population Sampling Survey conducted in 2005, there are approximately 150 million people from rural areas who are now living and working among China's 450 million urban residential populations (China National Bureau of Statistics, 2006). Different from many other countries, rural-to-urban migrants (termed as "rural migrants" thereafter) in China frequently move from one city to another, looking for new and or better opportunities $(\mathrm{Li}$, 2004; Zhang, 2001; Zhong, 2004). Rural migrants also visit their hometown in rural areas for special events (e.g., getting married) and during important holidays (e.g., Chinese New Year) and agriculture seasons (Chen, Stanton, Li, Fang, \& Lin, 2008; Li, 2003). The largescale and sustained domestic migration has created a "living bridge" between rural areas where the HIV infection in China was originated (Wu, Rou, \& Cui, 2004) and urban areas where large scale HIV epidemics are highly likely (Hong, Stanton, Li, Yang, Lin \& Fang, et al, 2006; Hu, Liu, Li, Stanton, \& Chen, 2006; Qian, Vermund, \& Wang, 2005; Thompson, 2004).

\section{HIV Risk Behaviors among Chinese Rural Migrants}

Data from diverse sources indicate that HIV risk behaviors are prevalent among Chinese rural migrants, including engagement in sexual behaviors and use of substances (Chen, Stanton, Li, Fang, Lin, Xiong, 2009; Chen, Stanton, Li, Fang \& Lin, 2008; Lin et al., 2005; Qian et al., 2005). A number of sexual risk behaviors have been reported among rural migrants in China. These include, but are not limited to, premarital sex, having sex with multi-partners, engaging in commercial sex, having sex under the influence of alcohol, and practicing unprotected sex $(\mathrm{Li}$, Fang, Lin, Mao, Wang, Cottrell et al, 2004; Lin, Li, Yang, Fang, Stanton \& Chen, 2005; Liu Li, Stanton, Fang, Mao \& Chen, 2005; Yang, Li, Stanton, Fang, Lin, Mao et al., 2005; Yang, Derlega, \& Luo, 2007).

Substance use and misuse that are directly (e.g., injection drug use) and/or indirectly (e.g., alcohol abuse and tobacco smoking) related to
HIV infection are also prevalent among rural migrants (Chen, Li, Stanton, Fang, Lin \& Cole, 2004; Chen, Stanton, Li, Fang, \& Lin, 2008; Lin et al., 2005; Qian et al., 2005; Yang, Latkin, Celentano \& Luo, 2006). In one of our previous studies, we have observed that 30-day alcohol intoxication rate among rural migrants was $36.7 \%$ for males and $16.8 \%$ for females; 30 -day smoking rate was $56.5 \%$ for males and $10.5 \%$ for females (Chen, Stanton, Li, Fang, \& Lin, 2008). The prevalence rates of all of these behaviors were 2 to 17 times higher than those among the Chinese populations in general (Chen, Stanton, Li, Fang, \& Lin, 2008). Use of illegal drugs, including injection drug use that directly leads to HIV infection, has also been reported among Chinese rural migrants (Chen, Stanton, Li, Fang, \& Lin, 2008; Yang et al., 2007).

\section{Leisure Activities and HIV Risk Behaviors}

Leisure time and leisure activities consist of an essential part of people's daily life (Brown, Balluz, Heath, Moriarty, Ford, Gile, et al, 2003; Brown, Brown, Heath, Balluz, Giles, Ford, et al, 2004; Sener, Terzioglu, \& Karabulut, 2007; Tessier, Vuillemin, Bertrais, Boini, Bihan, Oppert, et al, 2007). In addition to such functions as recreational and recuperative, leisure time allows an individual to connect with others in the society and to gain access to various needed resources (Grzech-Sukalo \& Nachreiner, 1997; Hosper, Klazinga, \& Stronks, 2007; Michelsen \& Bildt, 2003; Thorlindsson \& Bernburg, 2006). A number of studies have reported factors associated with HIV risk behaviors among Chinese rural migrants, including socioeconomic status (Chen et al., 2008), workplace and job type (Yang et al., 2005), mobility across cities (Li et al., 2006), and migrant stigma (Liu et al., 2005; Yang et al., 2006). However, little is known about whether and what types of leisure activities are associated with HIV risk behaviors. Although rural migrants may enjoy little leisure time (due to long-time and labor intensive work), such limited time may in fact serve as a window opportunity for migrants to engage in HIV risk behaviors. When conducting research in China (Li et al., 2004; Lin et al., 2005; Yang et al., 2005), we have observed that some migrants 
reported watching videos (often including $\mathrm{X}$ rated movies), wondering on the street, visiting entailment installments after work. Engagement in this type of activities may increase the likelihood for migrants to engage in HIV risk behaviors by increasing the exposure to pro-risk resources and environment. We have also observed that most migrants reported watching TV programs broadcasted to the general public (educational, informational and recreational) or doing chores at home after work. Engagement in such constructive leisure activities may prevent migrants from engaging in HIV risk behavior. Therefore, understanding leisure activities as a potentially modifiable factor and their association with HIV risk behaviors will be of great significance for interventionists to devise effective prevention programs.

\section{Purpose of this Study}

In this study, we focus on the association between leisure activities and HIV risk behaviors using cross-sectional survey data. We first described the patterns and levels of a group of leisure activities, followed by the prevalence levels of HIV risk behaviors. We then examined the associations between the two. The purpose of the study was to identify the leisure activities that were associated with different levels of likelihood to engage in HIV risk behaviors and to fill in the data gap on factors that predict HIV risk behaviors among rural migrants in China and to provide evidence to support future HIV prevention research. Based on data from our previous observational studies, we hypothesized that certain leisure activities (e.g., watching videos, play cards in groups, and visiting entertaining installments) are associated with increased likelihood of HIV risk behavior, because engaging in these activities during leisure time may lead to substance use (including drinking and smoking) and risky sexual behavior (including commercial sex and unprotected sex); while other leisure activities (e.g., watching television and listening to radio which are freely available and contain programs typical educational, informational and recreational) are associated with reduced likelihood of HIV risk behavior, because people who engage in these activities may obtain knowledge/skills from the mass media on HIV prevention while entertaining themselves.

\section{Method}

\section{Participants and Procedure of Data Collection}

Data used in this analysis were collected for an NIH funded research project regarding HIV/STD prevention among rural migrants in China. Details regarding the sampling and survey procedure have been described elsewhere (Li et al., 2004). Briefly, rural migrant workers were drawn from six of the eight urban districts in Beijing and eight of the nine urban districts in Nanjing. Beijing and Nanjian are two metropolitan cities in China. The participants were sampled at their workplaces (e.g., hotels, restaurants, hair salons, stores/shops, massage parlors, nightclubs, construction companies, factories, etc). A quota sampling procedure was used for sampling such that the proportion of sampled migrants from different work locations was close to that of the reported statistics from each of the two cities. All migrants were eligible to participate in the study if they were from a rural area, 18 to 30 years of age at the time of study, stayed in the city for at least one month, and the purpose was to work and earn money.

Data were collected in 2002 using the Migrant Health Behavior Survey, a self-administered paper-and-pencil questionnaire we developed and used in research (Li et al., 2004). Outreach strategies were utilized to reach the migrants at their worksites. Employers (or managers) at sampling units were contacted for permission. Among the employers reached, approximately $80 \%$ agreed to participate. Upon receiving permission, the investigators and trained data collectors went to the sampling units to recruit migrants and to administer the survey. To protect the participants, the survey was conducted in a private room in the work unit. If a private room was unavailable, the survey was conducted in a room either at residential housing or a place (often, a spare office room) the migrants felt comfortable. For participants with limited reading capabilities, the data collectors read the questions to them one by one and 
completed each survey question for them based on their responses. Written informed consent was obtained before survey was administered. Participants received a small monetary compensation (20 RMB or about \$2.5) following the completion of the questionnaire. Among the eligible rural migrants, $98 \%$ agreed to participate. The study protocol was approved by the Institutional Review Boards at West Virginia University in the United States and at Beijing Normal University and Nanjing University in China. Among the total 4,088 participants, 3 were excluded because of missing data. The remaining 4,085 participants were included in this analysis.

\section{Assessment of Leisure Activities}

Leisure activity was defined as those activities that migrants often engage in for relaxation, entraining, socialization, information, and recovery after work. The eleven leisure activities assessed in this analysis were: (1) watching television (free programs broadcasted through government-run stations that are typically informational, educational and entertaining), (2) watching videos (any available subjects, including $\mathrm{X}$-rated ones on video cassettes, video CDs or VCD, and digital video CD or DVD), (3) listening to radio programs (broadcasted by various local and national government stations covering news, music, song, opera, story, etc), (4) listening to audios (tape cassettes and CDs containing music, song, opera, story, etc), (5) reading (newspapers, books, magazines, etc); (6) chatting (usually with friends, co-workers and roommates), (7) playing cards (typically in groups with friends, co-workers, and roommates), (8) doing chores, (9) visiting entertainment installments (including bars, nightclubs, hair salons, massage parlors where commercial sex were available), (10) wandering on the street (a common practice in China among those who want to spend their free time alone or in small groups but have no money or are not willing to pay), and (11) simply sleeping at home. A checklist was used for the respondents to report their leisure activities. The selection of these activities was based on our focus-groups (using open-ended questions) and direct observation from site-visits during the afternoon and evening to typical places where rural migrants live and work, including employer provided dormitories, rentals, and simple self-made residential housing. These eleven activities were found to be common among rural migrants in urban settings. Other activities such as internet use, sports, going to movie theaters, were less common, they were therefore excluded.

\section{Assessment of HIV Risk Behavior}

Although engaging in any behavior that exposes the subject at increased risk of HIV infection can be considered as HIV risk behavior, we selected two types (sexual risk behavior and substance use/misuse) for this analysis. Data from our previous studies in China indicated that these two types of risk behavior were common among Chinese rural migrants (Chen et al., 2004; Chen et al., 2008; Lin et al., 2005).

Sexual Risk Behavior. Five commonly reported sexual behaviors among Chinese rural migrants were assessed and they were: engaging in premarital sex, having sex with multi-partners, ever sold sex, ever bought sex, and inconsistent condom use during sex. Participants were first asked if they ever had sex (yes/no). Those who responded positively were classified as sexually active. Among the sexually active migrants, those who reported having had sex before marriage were classified as having engaged in premarital sex; those who reported having had sex with two or more partners were classified as having multi-partner sex according to the reported number of sex partners in response to the question, "Have you ever had sex with how many partners?" Participants were categorized as having sold sex if they responded positively to the question "Have you ever had sex with someone and got paid or received materials in return?"; and participants were categorized as having bought sex if they respond positively to the question "Have you ever paid money or used materials to exchange for sex?" Participants were classified as inconsistent condom use if they reported condom use during sex less frequently than "always" in response to the question, "How often do you use a condom during sex?" (Answer options: "never", "occasional", "sometimes", "often" and "always") 
Substance Use/Misuse. Participants were classified as 6-months alcohol intoxicators if they reported getting drunk at least once in response to the question: "How many times did you get drunk during the last month?" $(1=$ did not get drunk, 2 = got drunk once, 3 = got drunk more than once). Because of the relatively low prevalence rate of illegal drug use, lifetime use was defined and used. Participants were classified as lifetime illegal drug users if they responded positively to the question: "Have you ever used illegal drugs (such as marijuana, opium and heroin, etc.)?" ( $1=$ yes and $2=$ no) Participants were classified as 30 -smokers if they reported smoking at least 1-5 cigarettes per day during the past month in response to the question: "How many cigarettes did you usually smoke per day during the past month?" $(1=$ not smoked, $2=1-5$ cigarettes, $3=6-10$ cigarettes, 4 $=11-15$ cigarettes, $5=16-20$ cigarettes, $6=$ more than 20 cigarettes).

\section{Statistical Analysis}

The patterns and levels of leisure activities and HIV risk behaviors were summarized using percentage rate, stratified by gender and the duration of migration. The three substance use behaviors were assessed for the total sample while the five sexual risk behaviors were assessed among the participants who were sexually active. The prevalence of HIV risk behaviors were further assessed against the years of migration to provide data on changes in these behaviors after migration. Associations between individual leisure activities and HIV risk behaviors were first explored using bivariate Chi square tests and further verified using multiple logistic regression models. In each multiple logistic regression model, an HIV risk behavior was entered as the dependent variable and all eleven leisure activities were entered as the independent variables. Since the number of participants who ever sold sex or bought sex was relatively few, the two behaviors were combined as one variable (termed as "commercial sex involvement") for multiple logistic regression analysis.

To obtain valid estimates of the association between leisure activities and an HIV risk behavior, five variables were included in the regression models as covariates, including age, years of schooling, if single, years of migration, and type of workplaces (i.e., hotels, restaurants, bars, nightclubs, beauty salons, massage parlors, domestic services, construction sites, and factories, indicated using a set of dummy variables). The study sites were not included as covariates because the subsamples of Beijing and Nanjing did not differ significantly in the HIV risk behaviors measures. Statistical analysis was conducted for male and female migrants separately to provide gender-specific data.

\section{Results}

\section{Characteristic of the Study Participants}

The main characteristics of the study sample are summarized in Table 1. Among the 4,085 participants included in the analysis, 1,655 $(40.5 \%)$ were female with a mean age of 23.4 years old $(\mathrm{SD}=3.5)$. Male participants were one year older than females (23.8 years vs. 22.8 years, $\mathrm{p}<.01$; data not shown in the table). Over $70 \%$ of the participants were single, with the majority of them having up to nine years of school education. More than half of the participants migrated to the city for less than three years, with an average of 2.9 years of migration $(\mathrm{SD}=2.3$, data not shown in Table 1$)$. Female migrants had a slightly shorter duration of migration than their male counterparts (2.9 vs. $3.1, \mathrm{p}<.01$; data not shown in the table). 
Table 1. Characteristics of the Study Sample

\begin{tabular}{|c|c|c|c|c|c|c|}
\hline \multirow{2}{*}{ Characteristics } & \multicolumn{2}{|c|}{ Total } & \multicolumn{2}{|c|}{ Female } & \multicolumn{2}{|c|}{ Male } \\
\hline & $\mathrm{N}$ & $\begin{array}{c}\text { Proportion } \\
(\%)\end{array}$ & $\mathrm{N}$ & $\begin{array}{c}\text { Proportion } \\
(\%)\end{array}$ & $\mathrm{N}$ & $\begin{array}{c}\text { Proportion } \\
(\%)\end{array}$ \\
\hline Overall & 4,085 & 100.0 & 1,655 & 40.5 & 2,430 & 59.5 \\
\hline \multicolumn{7}{|l|}{ Age (in years) } \\
\hline $18-24$ & 3,503 & 85.7 & 1,380 & 83.4 & 2,123 & 87.4 \\
\hline $25-30$ & 582 & 14.3 & 275 & 16.6 & 307 & 12.6 \\
\hline
\end{tabular}

Marital status

$\begin{array}{lllllll}\text { Never married } & 2,878 & 70.5 & 1,253 & 75.7 & 1,625 & 66.9\end{array}$

\section{Education*}

$\begin{array}{lrrrrrr}0-9 \text { yeas } & 2,483 & 61.4 & 951 & 58.1 & 1,532 & 63.6 \\ 10+\text { years } & 1,560 & 38.6 & 685 & 41.9 & 875 & 36.4\end{array}$

Years migrated to this city

$\begin{array}{lrrrrrr}<\text { 1 year } & 364 & 8.9 & 186 & 11.2 & 178 & 7.3 \\ \text { 1- year } & 948 & 23.2 & 415 & 25.1 & 553 & 22.8 \\ \text { 2- years } & 928 & 22.7 & 399 & 24.1 & 529 & 21.8 \\ \text { 3- years } & 649 & 15.9 & 264 & 16.0 & 385 & 15.8 \\ \text { 4+ years } & 1,176 & 28.8 & 391 & 23.6 & 785 & 32.3\end{array}$

Note: *participants with missing data were excluded.

Patterns and Levels of Leisure Activities

Data in Table 2 indicate that the number of migrants engaging in each of the eleven leisure activities varied greatly from less than $10 \%$ up to $60 \%$. Three activities with the highest rates of participation were: watching television $(60.2 \%)$, reading $(59.1 \%)$, and sleeping at home $(55.6 \%)$; and three activities with the lowest rates of participation were: visiting entertainment installments $(7.4 \%)$, playing cards in groups $(12.2 \%)$, and watching videos $(19.5 \%)$. There were gender differences in participating in five activities (watching TV, watching videos, simply sleeping after work, doing chores, and wondering on the street). 
Table 2. Participation (\%) in Various Types of Leisure Activities among Rural Migrants in Urban China

\begin{tabular}{|c|c|c|c|c|c|c|c|c|c|c|c|}
\hline & $\begin{array}{c}\text { Watching } \\
\text { TV }\end{array}$ & $\begin{array}{l}\text { Watching } \\
\text { video }\end{array}$ & $\begin{array}{l}\text { Listening } \\
\text { to radio }\end{array}$ & Reading & Chatting & Sleeping & $\begin{array}{c}\text { Playing } \\
\text { cards }\end{array}$ & Choiring & $\begin{array}{c}\text { Wandering } \\
\text { around }\end{array}$ & $\begin{array}{c}\text { Listening } \\
\text { to audio }\end{array}$ & $\begin{array}{c}\text { Visiting } \\
\text { entertaining } \\
\text { installment }\end{array}$ \\
\hline $\begin{array}{l}\text { Overall }^{\mathrm{a}} \\
(\mathrm{N}=4085)\end{array}$ & 60.2 & 19.5 & 26.2 & 59.1 & 45.0 & 55.6 & 12.2 & 20.2 & 32.2 & 27.7 & 7.4 \\
\hline Female & 63.5 & 6.1 & 26.4 & 58.4 & 46.0 & 57.7 & 6.0 & 31.6 & 38.6 & 29.1 & 6.8 \\
\hline Male & $58.0 * *$ & $22.6^{* *}$ & 26.0 & 57.0 & 44.2 & $54.0 *$ & $16.5^{* *}$ & $12.5^{* *}$ & $27.9 * *$ & 26.7 & 7.9 \\
\hline \multicolumn{12}{|c|}{ Years of migration ${ }^{b}$} \\
\hline$<1(\mathrm{~N}=166)$ & 58.4 & 17.5 & 28.9 & 62.1 & 47.6 & 35.5 & 7.8 & 14.5 & 31.3 & 39.8 & 4.8 \\
\hline $1-(\mathrm{N}=1213)$ & 57.9 & 17.0 & 27.7 & 59.8 & 47.1 & 42.5 & 9.7 & 19.9 & 34.1 & 32.2 & 7.0 \\
\hline 3- $(\mathrm{N}=1184)$ & 58.0 & 20.1 & 26.2 & 59.5 & 45.3 & 44.1 & 10.7 & 20.7 & 34.6 & 29.0 & 8.3 \\
\hline $5-(\mathrm{N}=745)$ & 60.5 & 22.5 & 25.5 & 55.2 & 42.5 & 48.3 & 13.3 & 20.7 & 31.0 & 23.4 & 7.8 \\
\hline $7+(\mathrm{N}=777)$ & $67.4^{* *}$ & $20.0^{*}$ & $23.8 * *$ & 60.6 & $43.0 *$ & $45.8 * *$ & $18.4 * *$ & 20.5 & $26.9 * *$ & $20.2 * *$ & 6.9 \\
\hline
\end{tabular}

Four leisure activities (watching television, watching videos, simply sleeping after work, playing cards with others) showed an increasing trend along with migration duration $(\mathrm{p}<.05$ or $\mathrm{p}<.01$ respectively from Cochran-Armitage Trend tests) while one leisure activity (listening to radios) showed a declining trend with migration duration ( $\mathrm{p}<.01$ from Cochran-Armitage Trend test).

\section{Prevalence of HIV Risk Behaviors}

Among the total sample, approximately half $(49.2 \%)$ were sexually active (ever had sex in life) at the time of survey. Among the sexually experienced migrants, more than two thirds (66.9\%) had premarital sex, approximately one third $(31.3 \%)$ had sex with more than one partner, $7.6 \%$ ever sold sex and $5.9 \%$ ever bought sex, and more than $90 \%$ did not always use a condom during sex. Among the total sample, $28.1 \%$ reported past month alcohol intoxication, $1.7 \%$ reported lifetime illegal drug use, and $37.4 \%$ reported past 30-day tobacco smoking. The percentage of migrants who were sexual active, not always using a condom, alcohol intoxication and tobacco smoking increased with the duration of migration and the prevalence of premarital sex, multi-partner sex, bought sex and sold sex declined with the duration of migration. Cochran-Armitage Trend tests indicated that these trends were statistically significant at $p<$ .05 or $\mathrm{p}<.01$ level. 
Table 3. Prevalence Rate (\%) of HIV Risk Behaviors Among Rural Migrants in Urban China

\begin{tabular}{|c|c|c|c|c|c|c|c|c|c|}
\hline & $\begin{array}{c}\text { Sexually } \\
\text { active }\end{array}$ & $\begin{array}{c}\text { Premarital } \\
\text { sex }\end{array}$ & $\begin{array}{l}\text { Multiple } \\
\text { partners }\end{array}$ & Sold sex & Bought sex & $\begin{array}{l}\text { Inconsistent } \\
\text { condom use }\end{array}$ & $\begin{array}{c}\text { Alcohol } \\
\text { intoxication }\end{array}$ & $\begin{array}{c}\text { Use of illegal } \\
\text { drugs }\end{array}$ & $\begin{array}{l}\text { Tobacco } \\
\text { smoking }\end{array}$ \\
\hline $\begin{array}{l}\text { Overall } \\
\text { sample }^{\mathbf{a}} \\
(\mathrm{N}=4085)\end{array}$ & 49.2 & 66.9 & 31.3 & 7.6 & 5.9 & 92.3 & 28.1 & 1.7 & 37.4 \\
\hline Female & 41.3 & 61.3 & 21.6 & 2.1 & 6.4 & 91.4 & 16.4 & 1.8 & 10.2 \\
\hline Male & $54.5^{* *}$ & $69.7 * *$ & $36.1 * *$ & $10.3^{* *}$ & 5.7 & 92.8 & $36.1 * *$ & 1.6 & $56.0 * *$ \\
\hline \multicolumn{10}{|c|}{ Years of migration ${ }^{b}$} \\
\hline$<1(\mathrm{~N}=166)$ & 20.0 & 77.4 & 45.2 & 9.7 & 6.5 & 90.9 & 17.5 & 0.0 & 18.7 \\
\hline $1-(\mathrm{N}=1213)$ & 30.3 & 75.9 & 36.3 & 8.5 & 8.0 & 89.2 & 27.8 & 1.5 & 28.9 \\
\hline $3-(\mathrm{N}=1184)$ & 43.0 & 76.0 & 32.7 & 7.9 & 6.2 & 93.3 & 27.2 & 1.5 & 37.8 \\
\hline $5-(\mathrm{N}=745)$ & 62.1 & 66.7 & 29.9 & 9.0 & 4.9 & 90.9 & 31.1 & 2.2 & 43.2 \\
\hline $7+(\mathrm{N}=777)$ & $81.8^{* *}$ & $55.0 * *$ & $27.9 *$ & 5.6 & 5.4 & $94.7 *$ & $29.6^{* *}$ & 2.1 & $48.6 * *$ \\
\hline
\end{tabular}

HIV risk behaviors over the time course (years) of migration.

\section{Association between Leisure Activities and HIV Risk Behaviors}

Data in Table 4 are the adjusted odds ratio (AOR) from 14 multiple logistic regression models assessing the association between the eleven leisure activities and each of the seven HIV risk behaviors respectively, stratified by gender. Watching videos, playing cards, wondering on the street, and visiting entertaining installments were positively associated with most of the seven HIV risk behavior measures with the AOR varying from 1.27 (95\% CI: 1.00 to 1.61, p $<.05)$ between the activity "playing cards" and alcohol intoxication among males to $5.0(95 \%$ CI: 2.14 to $11.72, \mathrm{p}<.01)$ between the activity "wondering on the street" and commercial sex involvement among females. Watching television, reading, chatting, and doing chores were negatively associated with most of the seven HIV risk behaviors with the AOR varying from 0.29 (95\% CI: 0.14 to $0.62, \mathrm{p}$ $<.01)$ between the activity "watching television" and use of illegal drugs among male migrants to 0.71 (95\% CI: 0.52 to $0.97, \mathrm{p}<.05$ ) between the activity "chatting with friends/coworkers" and alcohol intoxication among female migrants. These associations were independent from such significant covariates as age, years of education, marital status, years of migration, and type of workplaces. 


\section{Discussion and Conclusions}

\section{Associations between Leisure Activities and HIV Risk Behavior}

In this study, we reported data on the associations between the leisure activities and HIV risk behaviors using data collected in a sample of 4,085 rural-to-urban migrants from Beijing and Nanjing, two large metropolitan cities of China. In addition to providing new data on the level and pattern of eleven leisure activities, we have observed strong associations between several leisure activities and HIV risk behaviors. Leisure activities that were negatively associated with HIV risk behaviors were: watching television, reading, listening to radio programs, doing chores, most of which were individual-based, socially desirable, "constructive" and recreational. Leisure activities that were positively associated with HIV risk behaviors were: playing cards, wondering on the streets, and visiting entertaining installments, almost all of which were small group-based, not always socially desirable (e.g., watching X-rated videos and visiting entertaining places for commercial sex), and purely recreational or entertaining.

\section{Implications for Research on HIV Prevention}

Findings from this study provided data much needed for HIV prevention among rural migrants in China (Chen et al, 2008; Wu et al, 2004; Li et al, 2004). Leisure time represents a window opportunity to reach at-risk rural migrants scattered in the diverse urban settings. The associations between leisure activities and HIV risk behaviors imply that HIV prevention intervention research should consider leisure activities as a group of key modifiable factors. Since engaging in different leisure activities was associated with varying levels of likelihood to engage in HIV risk behaviors, effective interventions should include measures to encourage constructive and socially desirable leisure activities that are associated with reduced risk of HIV risk behaviors (e.g., reading books and news papers and doing chores after work), and to discourage other leisure activities that are often socially undesirable and are associated with increased risk of HIV risk behaviors (e.g., visiting entertaining installments, wondering on the streets). Since chatting among friends and coworkers during leisure time is associated with reduced risk of HIV risk, HIV prevention may use such "constructive" leisure chatting groups to deliver HIV prevention programs, in addition to the individualized intervention. Consistent with the diffusion model (Choi, Yep, \& Kumekawa, 1998; Rogers, 2000; Svenkerud \& Singhal, 1998; Valente \& Fosados, 2006), when topics regarding HIV prevention become part of the leisure chatting, it may quickly spread to others. In addition, attention should be paid to gender differences and changes in leisure activities over time when an HIV prevention program is developed and tested. For example, watching videos (including $\mathrm{X}$-rated videos) is particularly risky for male migrants while wondering on the streets is only risky for female migrants; engaging in certain risky leisure activities (e.g., playing cards in groups and watching videos) increased with years of migration while engaging other risky leisure activities (e.g., wondering around) declined with years of migration. Considering these factors may increase the efficiency of an HIV prevention program.

There are several limitations to this analysis. First, the measurements of leisure activities are limited. We only counted whether a participant engaged in a leisure activity and did not collect data from individual participants to assess changes in activities before and after migration, activity contents (e.g., type of television programs, video programs, books, and etc), settings (e.g., when, where, and with whom, etc), frequency and duration of engaging in an activity during the leisure time. Second, data used for this analysis are cross-sectional in nature. No causal relationship can be concluded between a leisure activity and HIV risk behavior without further verification with longitudinal data. Lastly, data used for this study were collected in two cities. Therefore, caution is needed when the study findings are generalized to rural migrants in other cities of China. Despite the limitations, this analysis is the first to document leisure activities among rural migrants in China as well as their associations with an array of HIV risk behaviors commonly reported among rural migrants. Findings of this 
analysis provided new data supporting further research to understand migration-related HIV spreading. The research findings are also of significant implications for HIV prevention intervention among rural migrants in China.

\section{Funding Support}

This study was supported by National Institute of Health/National Institute of Mental Health (grant \#: R01MH064878).

\section{Acknowledgement}

The authors are grateful to colleagues from Beijing Normal University Institute of Developmental Psychology and Nanjing University who devoted their effort in data collection. Dr. Ambika Marthur kindly assisted in English editing of the manuscript.

\section{References}

Brown, D. W., Balluz, L. S., Heath, G. W., Moriarty, D. G., Ford, E. S., Giles, W. H., et al. (2003). Associations between recommended levels of physical activity and health-related quality of life. Findings from the 2001 Behavioral Risk Factor Surveillance System survey. Prev Med, 37(5), 520-528.

Brown, D. W., Brown, D. R., Heath, G. W., Balluz, L., Giles, W. H., Ford, E. S., et al. (2004). Associations between physical activity dose and health-related quality of life. Med Sci Sports Exerc, 36(5), 890-896.

Chen, X., Li, X., Stanton, B., Fang, X., Lin, D., Cole, M., et al. (2004). Cigarette smoking among ruralto-urban migrants in Beijing, China. Prev Med, 39(4), 666-673.

Chen, X., Stanton, B., Li, X., Fang, X., Lin, D., \& Xiong, Q. (2009). A Comparison of health risk behaviors of rural migrants with rural residents and urban residents in China. Am J Health Behav, $33(1): 15-25$

Chen, X., Stanton, B., Li, X., Fang, X. Y., \& Lin, D. H. (2008). Substance use among rural-to-urban migrants in China: A moderation effect model analysis. Subst Use Misuse, 43(1), 105-124.

China National Bureau of Statistics (CNBS). (2006). Results from 2005 National 1\% Population Sampling Survey. Beijing: CNBS.

Choi, K. H., Yep, G. A., \& Kumekawa, E. (1998). HIV prevention among Asian and Pacific Islander American men who have sex with men: A critical review of theoretical models and directions for future research. AIDS Educ Prev, 10(3 Suppl), 19-30.

Grzech-Sukalo, H., \& Nachreiner, F. (1997). Structural properties of shift schedules, employment of partners, and their effects on workers' family and leisure activities. Int J Occup Environ Health, 3(Supplement 2), S67-S70.

Hong, Y., Stanton, B., Li, X., Yang, H., Lin, D., Fang, X., et al. (2006). Rural-to-urban migrants and the HIV epidemic in China. AIDS Behav, 10(4), 421-430.

Hosper, K., Klazinga, N. S., \& Stronks, K. (2007). Acculturation does not necessarily lead to increased physical activity during leisure time: a cross-sectional study among Turkish young people in the Netherlands. BMC Public Health, 7(147), 230.

Hu, Z., Liu, H., Li, X., Stanton, B., \& Chen, X. (2006). HIV-related sexual behaviour among migrants and non-migrants in a rural area of China: Role of rural-to-urban migration. Public Health, $120(4), 339-345$.

Li, P. L. (2003). Social Network and Social Position of Rural Migrants in China. Beijing, China: Chinese Academy of Social Sciences.

Li, X.N. (2004). Rural migrants living on isolated islands in urban China--Opinions of experts from the XXVIII International Psychology Association. Newsnetwork.

Li, X., Fang, X., Lin, D., Mao, R., Wang, J., Cottrell, L., et al. (2004). HIV/STD risk behaviors and perceptions among rural-to-urban migrants in China. AIDS Educ Prev, 16(6), 538-556.

Li, X., Stanton, B., Chen, X., Hong, Y., Fang, X., Lin, D., et al. (2006). Health indicators and geographic mobility of young rural-to-urban migrants in China. World Health and Population, 8(2): 1-31. 
Lin, D., Li, X., Yang, H., Fang, X., Stanton, B., Chen, X., et al. (2005). Alcohol intoxication and sexual risk behaviors among rural-to-urban migrants in China. Drug Alcohol Depend, 79(1), 103-112.

Liu, H., Li, X., Stanton, B., Fang, X., Mao, R., Chen, X., et al. (2005). Relation of sexual risks and prevention practices with individuals' stigmatizing beliefs towards HIV infected individuals: An exploratory study. Sexually Transmitted Infections, 81(6), 511-516.

Liu, H. J., Li, X. M., Stanton, B., Liu, H., Liang, G. J., Chen, X. G., et al. (2005). Risk factors for sexually transmitted disease among rural-to-urban migrants in China: Implications for HIV/sexually transmitted disease prevention. AIDS Patient Care and STDs, 19(1), 49-57.

Lurie, M.N., Williams, B.G., Zuma, K., Mkaya-Mwamburi, D., Garnett, G., Sturm, A.W.,et al. (2003). The impact of migration on HIV-1 transmission in South Africa: A study of migrant and nonmigrant men and their partners. Sex Transm Dis, 30(2):149-156.

Michelsen, H., \& Bildt, C. (2003). Psychosocial conditions on and off the job and psychological ill health: Depressive symptoms, impaired psychological wellbeing, heavy consumption of alcohol. Occup Environ Med, 60(7), 489-496.

Qian, H. Z., Vermund, S. H., \& Wang, N. (2005). Risk of HIV/AIDS in China: Subpopulations of special importance. Sex Transm Infect, 81(6), 442-447.

Rogers, E. M. (2000). Diffusion Theory: A theoretical approach to promote community-level change. In J. L. Peterson \& R. J. DeClemente (Eds.), Handbook of HIV Prevention. New York: Kluwer Academic/Plenum.

Sanchez MA, Lemp GF, Magis-Rodriguez C, Bravo-Garcia E, Carter S, Ruiz JD. (2004). The epidemiology of HIV among Mexican migrants and recent immigrants in California and Mexico. J Acquir Immune Defic Syndr, 4;37 (Suppl 4):S204-214.

Sener, A., Terzioglu, R. G., \& Karabulut, E. (2007). Life satisfaction and leisure activities during men's retirement: a Turkish sample. Aging Ment Health, 11(1), 30-36.

Soskolne V, Shtarkshall RA. (2002). Migration and HIV prevention programmes: Linking structural factors, culture, and individual behaviour--an Israeli experience. Soc Sci Med,55 (8):1297-1307.

Svenkerud, P. J., \& Singhal, A. (1998). Enhancing the effectiveness of HIV/AIDS prevention programs targeted to unique population groups in Thailand: Lessons learned from applying concepts of diffusion of innovation and social marketing. J Health Commun, 3(3), 193-216.

Tessier, S., Vuillemin, A., Bertrais, S., Boini, S., Le Bihan, E., Oppert, J. M., et al. (2007). Association between leisure-time physical activity and health-related quality of life changes over time. Prev Med, 44(3), 202-208.

Thompson, A. (2004). International security challenges posted by HIV/AIDS: Implications for China. China: An International Journal, 2(2), 287-307.

Thorlindsson, T., \& Bernburg, J. G. (2006). Peer groups and substance use: Examining the direct and interactive effect of leisure activity. Adolescence, 41(162), 321-339.

Valente, T. W., \& Fosados, R. (2006). Diffusion of innovations and network segmentation: The part played by people in promoting health. Sex Transm Dis, 33(7 Suppl), S23-31.

Weine S, Bahromov M, Mirzoev A. (2008). Unprotected Tajik male migrant workers in Moscow at risk for HIV/AIDS. J Immigr Minor Health, 10(5):461-468

Wu, X., \& Treiman, D. J. (2004). The household registration system and social stratification in China: 1955-1996. Demography, 41(2), 363-384.

Wu, Z., Rou, K., \& Cui, H. (2004). The HIV/AIDS epidemic in China: History, current strategies and future challenges. AIDS Educ Prev, 16(3 Suppl A), 7-17.

Yang, H., Li, X., Stanton, B., Fang, X., Lin, D., Mao, R., et al. (2005). Workplace and HIV-related sexual behaviours and perceptions among female migrant workers. AIDS Care, 17(7), 819-833.

Yang, H., Li, X., Stanton, B., Fang, X., Lin, D., \& Naar-King, S. (2006). HIV-related knowledge, stigma, and willingness to disclose: A mediation analysis. AIDS Care, 18(7), 717-724.

Yang, X., Derlega, V. J., \& Luo, H. (2007). Migration, behaviour change and HIV/STD risks in China. AIDS Care, 19(2), 282-288. 
Yang, X., Latkin, C., Celentano, D., \& Luo, H. (2006). Prevalence and correlates of HIV risk behaviors among drug users in China. AIDS \& Behavior, 10(1), 71-81.

Yang, Y. (2003). [Domestic population migration and urbanization in China]. Accessed on August 2, 2007 at http://www.cpirc.org.cn/paper14.htm.

Ying, J. (2003). [Migrants in urban China: A vulnerable group of population in society transitions of China that needs urgent attention]. Accessed on August 2, 2007 at http://www.chinasociology.com/rzgd/rzgd029.htm.

Zhang, L. (2001). Migration and privatization of space and power in late socialist China. American Ethnologist 28(1), 179-205.

Zhong, D. (2004). Cheap Labor and China's Industrialization (Research Report). Beijing: Dajun Economic Monitoring Center of Beijing.

Author Information

Xinguang Chen, $\mathrm{MD}, \mathrm{PhD}^{*}$

Xiaoming Li, $\mathrm{PhD}$

Bonita Stanton, MD

Prevention Research Center

The Carman and Ann Adams Department of Pediatrics

Wayne State University

4707 St. Antoine Street, Suite W534, Detroit, MI 48201, USA

Telephone: (313)-745-0564

Email: jimchen@med.wayne.edu

Xiaoyi Fang**, PhD and Danhua Lin, PhD

Institute of Developmental Psychology, Beijing Normal University, Beijing, China

Rong Mao, MS**

Institute of Mental Health, Nanjing University, Nanjing, China

* corresponding author in US; ** corresponding authors in China 


\section{Appendix A}

Table 4. Association between Leisure Activities and HIV Risk Behaviors Among Rural Migrants in China - Results from Multiple Logistic Regression

\begin{tabular}{|c|c|c|c|c|c|c|c|c|}
\hline \multirow[t]{2}{*}{ Leisure activities } & \multicolumn{2}{|c|}{ Pre-marital sex } & \multicolumn{2}{|c|}{ Multiple sex partners } & \multicolumn{2}{|c|}{ Commercial sex } & \multicolumn{2}{|c|}{ No condom } \\
\hline & AOR & $95 \% \mathrm{CI}$ & AOR & $95 \% \mathrm{CI}$ & AOR & $95 \% \mathrm{CI}$ & AOR & $95 \% \mathrm{CI}$ \\
\hline \multicolumn{9}{|l|}{ Female } \\
\hline Watching video & 1.26 & $(0.62,2.57)$ & 1.53 & $(0.86,2.71)$ & 2.04 & $(0.83,5.01)$ & 1.02 & $(0.50,2.09)$ \\
\hline Listening to radio & 0.73 & $(0.39,1.39)$ & 0.44 & $(0.23,0.87)$ & 0.38 & $(0.10,1.40)$ & 1.48 & $(0.74,2.97)$ \\
\hline Chatting & 0.95 & $(0.56,1.60)$ & 0.74 & $(0.45,1.21)$ & 0.46 & $(0.20,1.06)$ & 1.00 & $(0.54,1.83)$ \\
\hline Sleeping & 1.11 & $(0.66,1.84)$ & 1.00 & $(0.61,1.65)$ & 1.20 & $(0.52,2.74)$ & 0.70 & $(0.38,1.30)$ \\
\hline Playing cards & 1.02 & $(0.45,2.34)$ & 2.00 & $(0.95,4.21)$ & $3.71 * *$ & $(1.35,10.18)$ & 1.23 & $(0.46,3.24)$ \\
\hline Doing chores & 0.94 & $(0.57,1.55)$ & 0.65 & $(0.39,1.09)$ & $0.35^{*}$ & $(0.14,0.90)$ & 1.22 & $(0.67,2.23)$ \\
\hline Wandering & $1.72 *$ & $(0.98,3.04)$ & $1.84 *$ & $(1.12,3.04)$ & $5.00 * *$ & $(2.14,11.72)$ & 1.27 & $(0.68,2.35)$ \\
\hline installments & & & & & & & & \\
\hline \multicolumn{9}{|l|}{$\underline{\text { Male }}$} \\
\hline Watching TV & 0.84 & $(0.61,1.17)$ & $0.68 *$ & $(0.51,0.91)$ & 0.71 & $(0.48,1.04)$ & 0.82 & $(0.50,1.34)$ \\
\hline Watching video & $2.27 * *$ & $(1.51,3.43)$ & $1.80 *$ & $(1.31,2.46)$ & 1.12 & $(0.73,1.72)$ & 1.08 & $(0.64,1.84)$ \\
\hline \multirow[t]{2}{*}{ Listening to radio } & $0.64 *$ & $(0.43,0.95)$ & $0.72 *$ & $(0.51,1.00)$ & 1.16 & $(0.72,1.88)$ & & $(1.06,2.98)$ \\
\hline & & & & & & & $1.77 *$ & \\
\hline Reading & 1.05 & $(0.76,1.44)$ & $0.67 * *$ & $(0.50,0.88)$ & $0.61 * *$ & $(0.42,0.89)$ & 1.22 & $(0.75,1.99)$ \\
\hline
\end{tabular}




$\begin{array}{lllllllll}\text { Chatting } & 1.43^{*} & (1.04,1.98) & 1.21 & (0.92,1.60) & 0.69 & (0.46,1.02) & 0.97 & (0.60,1.55) \\ \text { Sleeping } & 1.05 & (0.77,1.44) & 1.17 & (0.89,1.54) & 0.87 & (0.60,1.27) & 0.88 & (0.55,1.41) \\ \text { Playing cards } & 1.34 & (0.90,2.01) & 1.55^{*} & (1.11,2.17) & 1.70^{*} & (1.10,2.61) & 0.69 & (0.36,1.32) \\ \text { Doing chores } & 0.79 & (0.51,1.22) & 0.42^{* *} & (0.27,0.66) & 0.69 & (0.37,1.31) & 0.73 & (0.36,1.49) \\ \text { Wandering } & 1.12 & (0.76,1.64) & 1.25 & (0.92,1.70) & 1.40 & (0.93,2.12) & 1.25 & (0.76,2.07) \\ \text { Listening to audio } & 1.27 & (0.83,1.94) & 1.35 & (0.96,1.89) & 0.56^{*} & (0.32,0.95) & 1.07 & (0.62,1.84) \\ \text { Visiting entertaining } & 0.63 & (0.32,1.25) & 1.48 & (0.95,2.30) & 1.83^{*} & (1.07,3.14) & 0.99 & (0.49,2.00) \\ \text { installments } & & & & & & & & \end{array}$

Table 4 Continued.

\begin{tabular}{|c|c|c|c|c|c|c|}
\hline \multirow{2}{*}{ Leisure activities } & \multicolumn{2}{|c|}{ Alcohol intoxication } & \multicolumn{2}{|c|}{ Use of illegal drugs } & \multicolumn{2}{|c|}{ Tobacco smoking } \\
\hline & AOR & $95 \% \mathrm{CI}$ & AOR & $95 \% \mathrm{CI}$ & AOR & $95 \% \mathrm{CI}$ \\
\hline \multicolumn{7}{|l|}{ Female } \\
\hline Watching TV & $0.61 * *$ & $(0.45,0.84)$ & $0.62 * *$ & $(0.27,1.47)$ & 0.82 & $(0.55,1.23)$ \\
\hline Watching video & $1.58 *$ & $(1.09,2.27)$ & $1.77 *$ & $(0.70,4.47)$ & $2.11 * *$ & $(1.37,3.25)$ \\
\hline Listening to radio & 0.71 & $(0.49,1.04)$ & 1.04 & $(0.37,2.90)$ & $0.61 *$ & $(0.36,1.00)$ \\
\hline Reading & 0.97 & $(0.71,1.32)$ & 0.83 & $(0.35,1.93)$ & 0.85 & $(0.57,1.25)$ \\
\hline Chatting & $0.71 *$ & $(0.52,0.97)$ & $0.96 *$ & $(0.42,2.21)$ & 0.75 & $(0.51,1.11)$ \\
\hline Sleeping & 1.08 & $(0.80,1.46)$ & 0.89 & $(0.39,2.01)$ & 1.02 & $(0.69,1.49)$ \\
\hline Playing cards & $2.28 * *$ & $(1.37,3.78)$ & $1.84 *$ & $(0.53,6.39)$ & $1.94^{*}$ & $(1.05,3.60)$ \\
\hline Doing chores & 1.12 & $(0.81,1.54)$ & 0.47 & $(0.16,1.34)$ & $0.62 *$ & $(0.41,0.96)$ \\
\hline Wandering & 1.27 & $(0.94,1.73)$ & 0.66 & $(0.27,1.63)$ & 1.45 & $(0.98,2.13)$ \\
\hline Listening to audio & 1.09 & $(0.77,1.55)$ & 1.24 & $(0.46,3.36)$ & 1.02 & $(0.64,1.61)$ \\
\hline
\end{tabular}




\begin{tabular}{|c|c|c|c|c|c|c|}
\hline $\begin{array}{l}\text { Visiting entertaining } \\
\text { installments }\end{array}$ & $2.64 * *$ & $(1.67,4.18)$ & $3.32 * *$ & $(1.04,10.6)$ & $2.66 * *$ & $(1.55,4.55)$ \\
\hline Male & & & & , & & \\
\hline Watching TV & 0.86 & $(0.71,1.04)$ & $0.29 * *$ & $(0.14,0.62)$ & 0.91 & $(0.76,1.10)$ \\
\hline Watching video & $1.36 * *$ & $(1.09,1.70)$ & $2.18^{*}$ & $(1.00,4.82)$ & $1.61 * *$ & $(1.28,2.02)$ \\
\hline Listening to radio & 0.92 & $(0.74,1.15)$ & $2.76^{*}$ & $(1.25,6.11)$ & $0.78^{*}$ & $(0.63,0.96)$ \\
\hline Reading & $0.64 * *$ & $(0.53,0.76)$ & $0.42 *$ & $(0.20,0.88)$ & $0.75 * *$ & $(0.62,0.90)$ \\
\hline Chatting & 0.97 & $(0.81,1.17)$ & $0.45^{*}$ & $(0.20,1.00)$ & 0.94 & $(0.79,1.13)$ \\
\hline Sleeping & 0.92 & $(0.77,1.10)$ & 0.73 & $(0.36,1.49)$ & 0.98 & $(0.82,1.18)$ \\
\hline Playing cards & $1.27 *$ & $(1.00,1.61)$ & 0.83 & $(0.33,2.08)$ & $1.75 * *$ & $(1.36,2.26)$ \\
\hline Doing chores & $0.70 *$ & $(0.53,0.93)$ & 1.33 & $(0.47,3.75)$ & 0.86 & $(0.66,1.13)$ \\
\hline Wandering & 0.99 & $(0.81,1.22)$ & $2.15^{*}$ & $(1.02,4.54)$ & 1.10 & $(0.90,1.35)$ \\
\hline Listening to audio & 0.91 & $(0.73,1.13)$ & 0.54 & $(0.19,1.55)$ & 0.85 & $(0.69,1.04)$ \\
\hline $\begin{array}{l}\text { Visiting entertaining } \\
\text { installments }\end{array}$ & $1.37 *$ & $(1.00,1.91)$ & $3.04 * *$ & $(1.19,7.75)$ & $1.87 * *$ & $(1.29,2.73)$ \\
\hline
\end{tabular}

Note: One logistic regression model was used for each of the seven HIV risk behaviors respectively, the 11 leisure activities were all included in each model. AOR: Adjusted odds ratio after controlling for age, education, marital status, years of migration to urban areas, and work locations. *: p<.05 and **: p<.01. 